\title{
Knowledge about and attitudes toward mental disorders among Nagas in North East India
}

\author{
Imlisongla Longkumer ${ }^{1}$, Indranee Phookan Borooah ${ }^{2}$ \\ ${ }^{1}$ Assistant professor, Department of Psychology, Nagaland University, Nagaland, India \\ ${ }^{2}$ Professor, Department of Psychology, Gauhati University, Assam, India
}

\begin{abstract}
The present study surveyed knowledge and attitudes toward mental disorders among Nagas. The sample comprised of 500 adults above 21 years of age and included both males $(n=226)$ and females $(n=$ 272). The distribution of the 500 participants according to their educational qualification was - up to Middle School $(n=136) ;$ up to High School $(n=164)$; Graduate and above $(n=198)$. A case vignette of schizophrenia was used and participants were asked to respond to a questionnaire based on the vignette. Percentage frequencies of responses were worked out for every item on the questionnaire for analysis. A great majority could recognize a mental health problem in the case vignette but used more general terms such as psychological problem/ mental problem/ mental illness. Majority attributed the problem to psychosocial factors and chose a psychiatrist/psychologist over other options. However, a considerable number of participants reported evil spirit possession as the cause of mental disorders and preferred seeking for divine intervention as a treatment mode. Chi-square test was applied to see the relationship of educational level with attitudes toward mental disorders. Results showed significant differences in attitudes when compared by educational level.
\end{abstract}

Key words: Knowledge, attitude, mental disorders, education, Nagas

\section{Introduction}

Mental disorders, which can take the form of anxiety, depression, phobia, mania, schizophrenia, and so on, can affect anybody and are common worldwide causing suffering and misery to millions across the world. A report by the World Health Organization shows that 20 percent of all patients seen by primary health care providers have one or more mental health disorders and that 25 percent of people are affected by mental disorders at some time during their lives ${ }^{[1]}$. Mental disorders can cause a great deal of suffering to those afflicted with such disorders and can also be a source of burden to the families, friends and care takers of those afflicted. In fact, mental disorders such as depression fall amongst the top leading causes of the global disease burden ${ }^{[2]}$. Moreover, it is estimated that the proportion contributed by mental disorders to the total global disease burden will increase from 10.5 percent in 1990 to 15 percent in $2020^{[2]}$. Unfortunately, however, mental disorders are often shrouded with myths and misconceptions leading to negative attitudes towards those suffering from such disorders. Many people with mental disorders are often stigmatized and discriminated by people around them that they are forced to live in shame and suffering. Moreover, the negative attitudes of other people and the stigma associated with mental disorders often act as barriers to seeking appropriate help and treatment. Mental health is an essential component of health and wellbeing and so early identification and treatment of mental disorders is important. This will happen only when people have adequate knowledge and positive attitudes regarding mental disorders. Previous studies indicate that successful planning and implementation of community based mental health programs will require an adequate knowledge of public attitudes to mental disorders and its treatment ${ }^{[3,4,5]}$. An accurate assessment of public knowledge about mental disorders and their attitudes toward such disorders is, therefore, important to plan and implement programs relating to mental health in general and mental disorders in particular. Persistent negative attitudes toward the mentally ill have often been reported by studies done on attitudes toward mental disorders and towards people with mental disorders ${ }^{[6]}$ which is often attributed to lack of knowledge regarding mental health and mental disorder ${ }^{[5]}$. Surveys in several countries have shown that many members of the public do not correctly recognize mental disorders ${ }^{[7]}$. Some recent studies, however, have demonstrated considerable changes in public attitudes toward mental disorders ${ }^{[6,8]}$ and this improvement in attitudes have been attributed to public education programs regarding mental health literacy. Attitudes towards mental illness and psychotherapy are reported to be related with help seeking behavior ${ }^{[9]}$ and formal education is also reported to have positive relationship with opinions of psychological disorders and treatment $t^{[4,10,11,12,13]}$.

Although there are many studies on knowledge and attitudes regarding mental disorders conducted in different parts of the world, little is known about the knowledge and attitudes of the Nagas with respect to mental disorders. The Nagas are a group of tribal people living in the north eastern part of India. Tribal culture and beliefs were predominant amongst the Naga tribes until about the end of the nineteenth century. With 
changing times, a great majority of them have now adopted Christian culture and beliefs and many receive formal education that reshape their thinking and outlook to life in general. This study was aimed at exploring the existing knowledge and attitudes they have regarding mental disorders and to see whether formal education has any relationship with their attitudes toward such disorders.

\subsection{Participants}

\section{Method}

The sample comprised of 500 participants from the Ao-Naga tribe, one of the most prominent tribes of Nagaland. The participants were all Christians above 21 years and included both males $(\mathrm{n}=226)$ and females $(\mathrm{n}=272)$. The distribution of the 500 participants according to their educational qualification was - up to Middle School $(\mathrm{n}=136)$; up to High School $(\mathrm{n}=164)$; and Graduate and above $(\mathrm{n}=198)$.

\subsection{Materials}

The research tool used in the study included a brief instruction, respondent's personal identification chart, a case vignette and a questionnaire based on the vignette.

The case vignette selected for this study was adapted from an Australian study by Jorm and Wright (2008) ${ }^{[14]}$. The vignette, which had been originally prepared to meet DSM-IV criteria and validated by mental health professionals, was slightly modified to suit the respondents of the Naga community.

"Sangpang is a 15 year old who lives at home with his parents. He has been attending school irregularly over the past year and has recently stopped attending altogether. Over the past 6 months he has stopped seeing his friends and begun locking himself in his bedroom and refusing to eat with the family or to have a bath. His parents hear him walking about in his bedroom at night while they are in bed. Even though they know he is alone, they have heard him shouting and arguing as if someone else is there. He has become unreasonably suspicious and talks incoherently. When they try to encourage him to do more things he whispers that he won't leave home because he is being spied upon by the neighbors. His face is expressionless most of the time and sometimes he giggles at rather inappropriate times"

A questionnaire based on the case vignette was also prepared and all items in it related to the person in the vignette. The items included were pertaining to identification of the problem, perceived causes, preferred treatment options, exposure to mental disorders, acceptance in friendship and marriage, and items relating to perceived dangerousness, fear, avoidance, punishment and shame.

The research tool was validated by several subject experts and a pilot study on thirty adults belonging to the Ao-Naga tribe. It was then translated in Ao- Naga dialect and items were presented alternately in English and Ao-Naga.

\subsection{Procedure}

The research tool was distributed to 850 Ao-Nagas residing in four Ao-Naga villages and four towns of Nagaland. They were asked to read the vignette and then respond to the questions. The first 500 responses were taken as the sample for this study. Simple percentages were worked out for each item on the questionnaire; these percentages were then tested for significance using the .95 confidence interval. The Chi-square test was also applied to selected items on the questionnaire.

\section{Results}

The items in the questionnaire were divided into six categories for analysis:

$>$ Identification or description of the problem depicted in the vignette.

$>$ Perceived causes of the problem depicted in the vignette.

$>$ Preferred treatment options for persons with problems like the one depicted.

$>$ Exposure to mental disorders.

$>$ Attitudes reflecting acceptance of persons with problems like the one in the vignette.

$>$ Attitudes reflecting stigma, fear and discrimination.

Percentages of responses and their confidence intervals were worked out for all items in each category.

For items in the last two categories, percentages of responses were categorized by educational level (Middle school, High school and Graduate and above). Chi Square $\left(\mathrm{X}^{2}\right)$ test was then applied to see significant differences by educational level with regard to beliefs and attitudes towards mental disorders.

\subsection{Identification or description of the problem depicted in the vignette}

Nearly three fourth of the participants could recognize that there was a mental health problem, but most of them used general terms such as mental problem/psychological problem/ mental illness/mental imbalance to describe the person's problem. Only a very small proportion used psychological terms such as schizophrenia /psychosis to describe the person's problem. Evil spirit possession, drug addiction, laziness, frustration, 
inferiority complex, HIV/AIDS, cancer, etc. were the other descriptions identified in the responses. Table 1 shows percentage and .95 Confidence Interval (CI).

Table 1 Identification/description of the problem depicted in the vignette

\begin{tabular}{|c|c|c|c|}
\hline Responses & $\begin{array}{l}\% \\
(\mathrm{n}=500\end{array}$ & & $.95 \mathrm{CI}$ \\
\hline Schizophrenia/Psychosis & 3.6 & & \pm 1.15 \\
\hline $\begin{array}{l}\text { Mental/Psychologicalproblem/Mentalretardation/Mental } \\
\text { imbalance/Mad }\end{array}$ & 64 & $\begin{array}{l}\text { 67.6(Mental } \\
\text { health problem) }\end{array}$ & \pm 4.21 \\
\hline Possessed & 8.4 & & \pm 2.43 \\
\hline $\begin{array}{l}\text { Lazy, frustrated, having inferiority complex, lonely, shy, suspicious, does } \\
\text { not have any problem }\end{array}$ & 15 & & \pm 3.14 \\
\hline Drug addiction & 3.6 & & \pm 1.63 \\
\hline Love Sickness & 1 & & \pm .86 \\
\hline HIV/AIDS, Cancer & 1.8 & & \pm 1.15 \\
\hline Can't say & 2.6 & & \pm 1.39 \\
\hline
\end{tabular}

\subsection{Description of the cause for the problem depicted in the vignette}

Psychosocial factors like frustration, lack of self esteem, tension, family conflicts, lack of parental guidance, abuse, poverty, etc. were identified, either singly or in combination, in about three quarters of the responses as the cause of the problem depicted in the vignette .Evil spirit possession and black magic spell, curse or ill luck, genetics, poisoning and misuse of drugs and alcohol, and malfunction of the brain were the other factors identified in the responses. A small proportion could not give any response to the question. Table 2 shows percentage and $.95 \mathrm{CI}$.

Table 2 Description of the cause for the problem depicted in the vignette

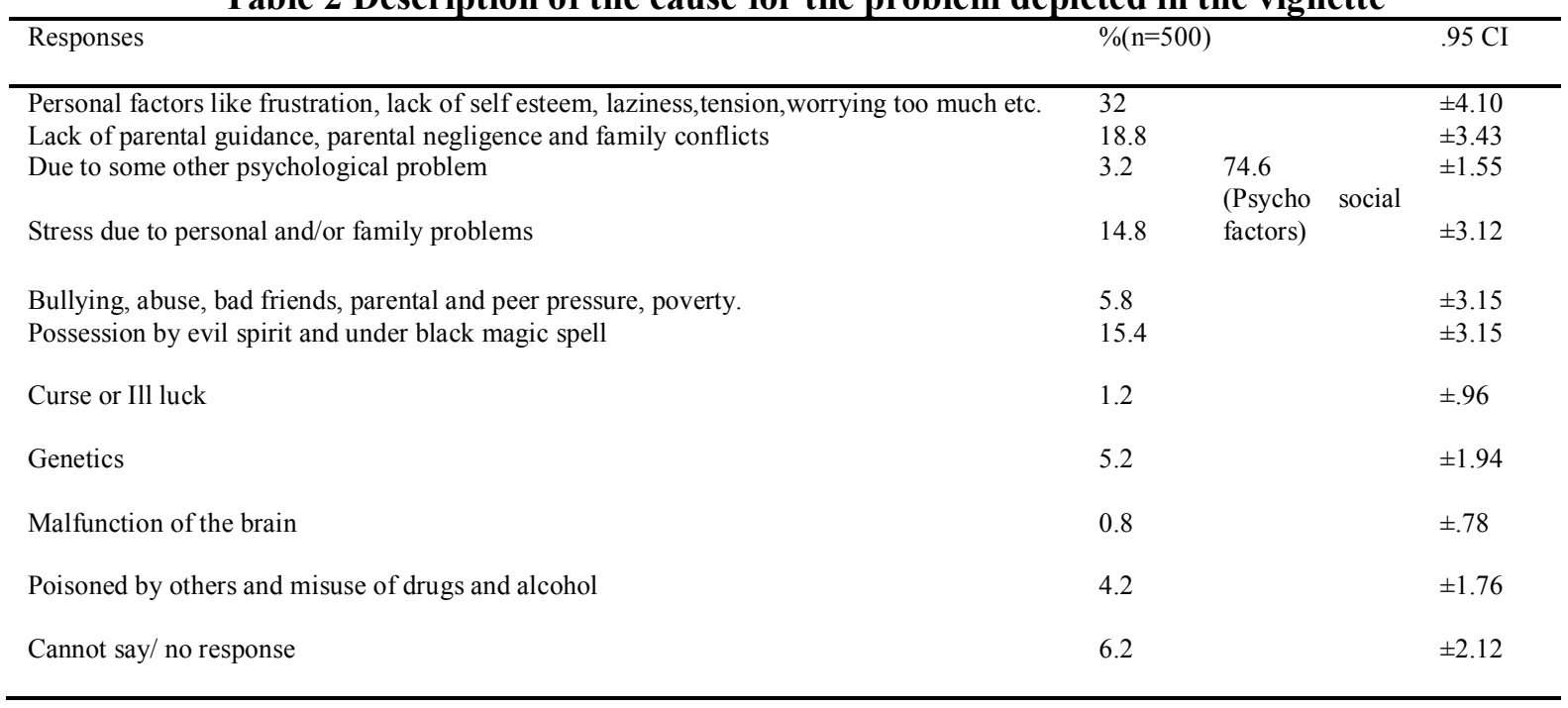

\subsection{Preferred treatment for persons with same or similar problems like the one in the vignette}

About half the participants endorsed seeking a psychiatrist or a psychologist as the sole preferred treatment option while 10.6 percent reported that they would seek a prayer group together with seeking a mental health practitioner. About a quarter preferred to go to a prayer group only. In all, preference for seeking a psychiatrist/psychologist was identified in 57.4 percent of responses while prayer group was identified in 35.8 percent. Seeking a physician or a general practitioner was endorsed by 7.6 percent and a small proportion reported they would go to a black magician or a traditional healer. Other suggested measures included giving proper guidance to the person, getting him married, and inflicting physical punishment. Table 3 shows percentage and $.95 \mathrm{CI}$ for each response category. 
Knowledge about and attitudes toward mental disorders among Nagas in North East India

Table 3 Preferred treatment for persons with same or similar problems like the one in the vignette

\begin{tabular}{lll}
\hline Responses & $\%(\mathrm{n}=500)$ & $.95 \mathrm{CI}$ \\
\hline Seek a physician or general practitioner & 7.6 & \pm 2.32 \\
Seek a psychiatrist/ psychologist & 46.8 & \pm 4.37 \\
Seek a psychiatrist/psychologist and prayer group & 10.6 & \pm 2.70 \\
Seek a prayer group & 25.2 & \pm 3.80 \\
Seek a black magician to dispel evil spirit/ & 4.4 & \pm 1.80 \\
Seek a traditional healer & & \\
Others: Proper guidance/ get married/ Punishment & 5.4 & \pm 1.98 \\
\hline
\end{tabular}

\subsection{Exposure to mental disorders}

Only 2 percent reported to have suffered from problems similar to the one depicted but half the participants reported knowing at least someone who had suffered from the same or similar problems. Table 4 shows percentage and $.95 \mathrm{CI}$.

Table 4 Exposure to mental disorders

\begin{tabular}{|c|c|c|}
\hline Items & $\begin{array}{l}\text { \% agreeing } \\
(\mathrm{n}=500)\end{array}$ & $.95 \mathrm{CI}$ \\
\hline Ever suffered from a problem similar to the one depicted in the vignette & 2 & \pm 0.87 \\
\hline $\begin{array}{l}\text { Know anyone who has, at one time or the other, suffered from the same } \\
\text { or a similar problem as depicted in the vignette }\end{array}$ & 49.8 & \pm 0.62 \\
\hline
\end{tabular}

\subsection{Attitudes indicating acceptance of the person in the vignette or others with similar problems}

More than half the participants reported that they would befriend the person. However, when it comes to the question of considering marriage, only 19.2 percent responded positively and even among them more than a quarter would not allow their children to marry one. Table 5 shows percentage and $.95 \mathrm{CI}$.

Table 5 Attitudes indicating acceptance of the person in the vignette or others with similar problems

\begin{tabular}{lll}
\hline Items & $\begin{array}{c}\text { \%agreeing } \\
(\mathrm{n}=500)\end{array}$ & $.95 \mathrm{CI}$ \\
\hline $\begin{array}{l}\text { Consider friendship with the person or with someone having similar problems. } \\
\begin{array}{l}\text { Willing to marry/ allow one's children to marry someone who has, at one time or the other, } \\
\text { suffered from a problem like the one depicted in the vignette. }\end{array}\end{array}$ & $\begin{array}{l}19.2 / 5.8 \\
\end{array}$ & \pm 3.22 \\
\hline
\end{tabular}

\subsection{Attitudes indicating stigma, fear and discrimination}

Not many participants endorsed the ideas of keeping the person behind locked doors, giving physical punishment or avoiding the person. However, half the participants believed that people like the one depicted in the vignette are more dangerous than others and that they were scared of people with such problems. More than a quarter of participants also attached the stigma of shame to such disorders .Table 6 shows percentage and .95 CI.

Table 6 Attitudes indicating stigma, fear and discrimination

\begin{tabular}{|c|c|c|}
\hline Items & $\begin{array}{l}\text { \%agreeing } \\
(n=500)\end{array}$ & $.95 \mathrm{CI}$ \\
\hline Keeping the person behind locked doors will be a good option. & 10.6 & \pm 2.74 \\
\hline Physical punishment can rectify the person's problem. & 4.6 & \pm 1.91 \\
\hline Persons like the one in the vignette are more dangerous than other people. & 53.4 & \pm 4.37 \\
\hline Feel scared to be with people like the person in the vignette. & 50 & \pm 4.38 \\
\hline Having a problem like the one depicted in the vignette is something to be ashamed of. & 32.8 & \pm 4.17 \\
\hline Best to avoid the person so that you don't develop this problem yourself. & 13 & \pm 2.95 \\
\hline
\end{tabular}

\subsection{Differences in attitudes - by educational level}

Significantly more number of those with graduate and above education compared to those with high school level and middle school level education endorsed the views that that they will accept the person in 
friendship $\left(X^{2}=9.94, P<.01\right)$ and in marriage $\left(X^{2}=21.6, P<.01\right)$. Fig. 1 shows percentages of participants endorsing acceptance in friendship and marriage.

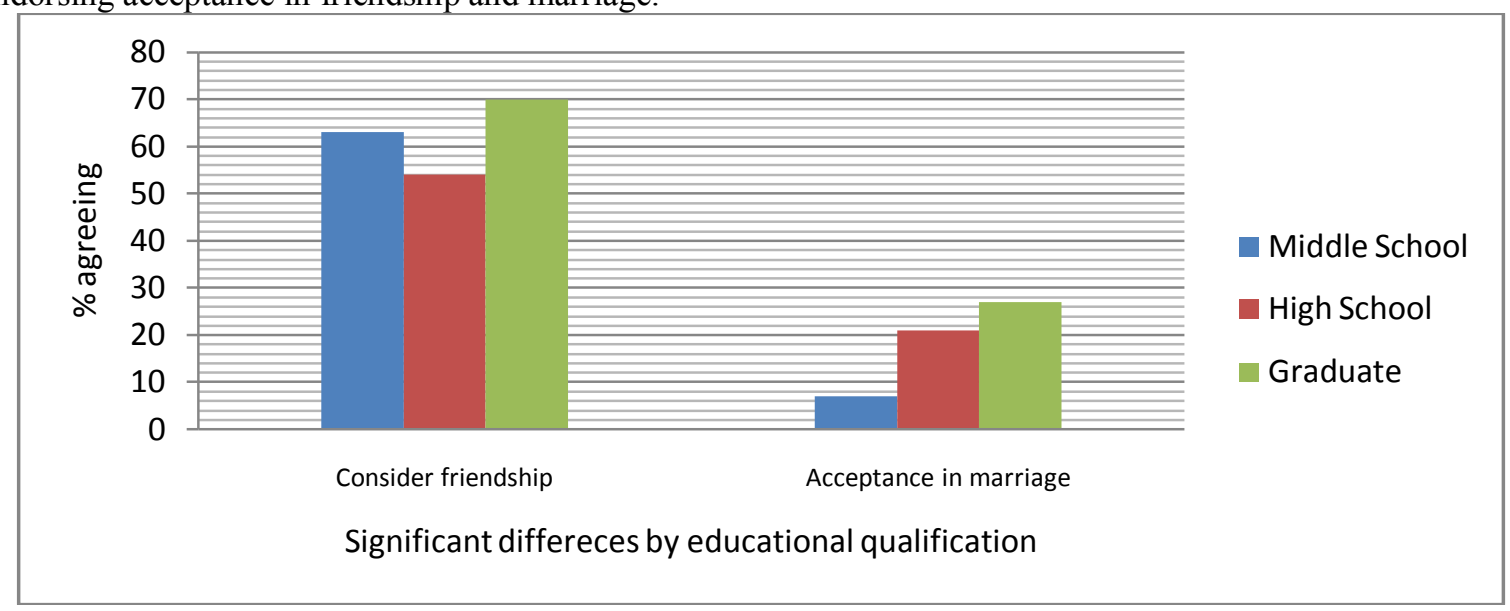

Figure 1 Significant differences in attitudes indicating acceptance - by educational level

Significantly less number of graduates and post-graduates compared to those with high school or middle school education endorsed the ideas of keeping the afflicted behind locked doors $\left(X^{2}=16.37, P<.01\right)$ and using physical punishment $\left(X^{2}=34.11, P<.01\right)$. Also significantly less number of graduates and postgraduates compared to participants with high school or middle school education endorsed the views that persons like the one depicted in the vignette are more dangerous than others $\left(X^{2}=25.54, P<.01\right)$, that they are scared of such persons $\left(X^{2}=41.18, P<.01\right)$, that having such a problem is shameful $\left(X^{2}=107.63, P<.01\right)$ or that it is best to avoid such persons $\left(X^{2}=9.22, P<.01\right)$. Fig. 2 shows percentages of participants endorsing attitudes and beliefs indicating stigma, fear and discrimination.

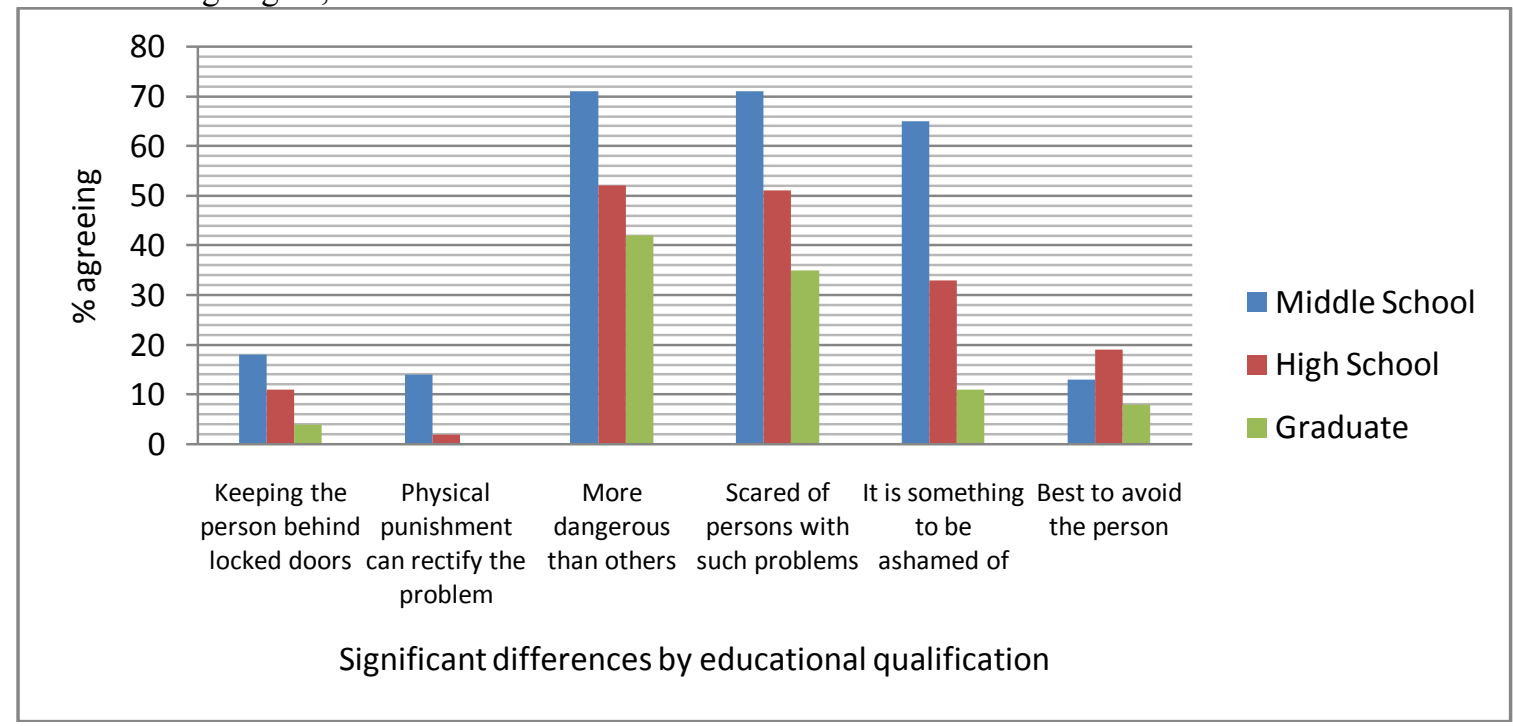

Figure 2 Significant differences in attitudes indicating stigma, fear and discrimination by educational level

Education seems to play a significant role with respect to stigma, fear and discrimination of those afflicted with mental disorders and also with respect to acceptance of such persons. Those with higher educational levels tend to have less stigmatizing attitudes and less discrimination towards people with mental disorders and are also more willing to accept them in friendship and marriage.

\section{Discussion}

Majority of the participants could recognize a mental health problem in the case depicted in the vignette. Perhaps this is due to their exposure to persons having similar problems as half of them reported having known at least someone who had suffered from the same or similar problem. In this light, it may be noted that individuals who have had previous contact with the mentally ill tend to hold more enlightened view

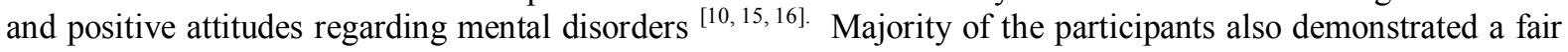
amount of knowledge regarding the cause of the problem in the vignette with most attributing it, either singly or in combination, to psychosocial factors and biological factors. The treatment option of seeking a psychiatrist or 
a psychologist chosen by most participants also reflects their knowledge about mental disorders. However, it may be noted that a considerable proportion of participants endorsed evil spirit possession as the cause and prayer as the sole treatment, and so this needs to be addressed. Prayer is an important part of life for most Nagas and irrespective of their level of religiosity, many seek for divine intervention through prayer in times of ill health. While prayer can have a cathartic effect for mild emotional and psychological problems, its role in treating severe psychological problems like psychosis and schizophrenia is not clear. The public need to be informed about the treatment options available so that they can make the right choice and seek early intervention. More than a quarter of the respondents in the study also could not recognize the case as a mental health problem indicating a lack of knowledge about mental disorders among a considerable proportion of the population. Even those who could recognize the case as a mental health problem could not specifically identify it. This highlights the need for public education on mental health and mental disorders. The public need to have the knowledge about mental disorders to allow them to recognize such problems and seek early help.

Reservations have been shown by a great majority with regard to acceptance in marriage. Moreover, negative attitudes such as fear of the person, perception of the condition as shameful and the person as dangerous have also been reported by a fair proportion of the respondents. Such negative attitudes are indicators of lack of appropriate knowledge about mental disorders among a considerable proportion of the society and may be corrected through proper educational programs. One significant finding of the study was the relationship of educational level with knowledge and attitudes regarding mental disorders. This is in congruence with results shown in similar studies in other parts of the world ${ }^{[4,10,11,12,13]}$. Results from the present study showed significant differences by educational level with regard to acceptance of afflicted persons as well as with regard to stigma, fear and discrimination. . Significantly more number of respondents with higher educational level expressed more willingness for acceptance in friendship and marriage as compared to others with lower educational qualification .Moreover, those with higher educational levels tend to hold less stigmatizing beliefs and less discriminatory attitudes towards people with mental disorders.

The role of education and mental health literacy in fostering positive attitudes toward mental disorders and those afflicted with such disorders have been demonstrated by a number of studies ${ }^{[8,17,18]}$. Proper mental health education programs need to be planned and implemented in the Naga community with special emphasis on mental disorders, its causes and treatment, so that the public become more aware of such problems and seek timely appropriate treatment.

\section{Conclusion}

The findings of the present study highlighted the existing attitudes and common beliefs regarding mental disorders among the Nagas and have indicated the role of formal education on attitudes toward the mentally ill. Majority of respondents in this study seems to have a fair amount of knowledge regarding mental disorder, however, some beliefs and attitudes among a considerable proportion of respondents reflect inaccurate knowledge and these need to be addressed.

Hence it is suggested that educational programs aimed at providing information about mental disorders and the mentally ill may be organized in educational institutions like Schools and Colleges, and also in the Church. Mass media programs such as television and radio talk, and newspaper articles on mental health issues may be done on a regular basis. Advocacy programs for early treatment may be taken up at the community level too.

\section{Acknowledgement}

The study was supported by the Indian Council of Social Science Research in the form of General Fellowship Grant to the lead author.

\section{References}

[1] WHO: [http://www.who.int/whr2001/2001/] webcite The World Health Report 2001. Mental health: New understanding; new hope WHO, Geneva in Kabir, M., Iliyahu,Z., Abubaker, I.S., and Aliyu, Z. (2004). Perception and beliefs about mental illness among adults in Karfi village, Northern Nigeria. BMC International Health and Human Rights.w w w. b i o m e d c e nt ra 1 . c o m/14 72 $698 \mathrm{X} / 4 / 3$.

[2] Murray,J.L. and Lopez,A.D. (1996). The Global Burden of Diseases: A comprehensive assessment of mortality and disability from diseases, injuries, and risk factors in 1990 and projected to 2020 .

[3] Bhugra,D. (1989) Attitudes towards mental illness. A review of the literature [review]. Acta Psychiatr Scand ,80:1-12. PubMed Abstract

[4] Trute,B, Teffte,B, Segall,A. ( 1989). Social rejection of the mentally ill: a replication study of public attitude. Soc Psychiatry Psychiatric Epidemiology, 24(2):69-76. PubMed Abstract

[5] Wolff,G., Pathare,S., Craig,T., Leff,J. (1996).Community knowledge of mental illness and reaction to mentally ill people. $B r J$ Psychiatry. PubMed Abstract.

[6] Ineland,1., Jacobsson,L.,Renberg,E.S. and Sjolander,P.( 2008). Attitudes towards mental disorders and psychiatric treatment- changes overtime in a Swedish population. Nordic Journal of psychiatry, 62(3): 192-197

[7] Jorm,A. F. (2000). Public knowledge and beliefs about mental disorders. British Journal of Psychiatry , 177:396-401 
[8] Madianos,M.G., Economoer,M., Hatjiandreou,M., Papageorgion, A., and Rogakon,E. ( 1999). Changes in public attitudes towards mental illnesss in Athens area.( 1999) Acta Psychiatrica Scandinavica, 99(1); 73-73

[9] Anthony,F.J., Medway,J., Christensen,H., Korten,A.E., Jacomb,P.A.,and Rodgers,B. (2000) in Mori,L. and Panova,A.(2007). Perception of mental illness and psychotherapy in a sample of Asian, Hispanic and White American college students. Journal of Psychiatry, Psychology and Mental Health. 1(2)

[10] Trute,B. and Loewen,A. (1978). Public attitudes toward the mentally ill as a function of prior personal experience. Social Psychiatry. 13(2): 79-84

[11] Furham,A. and Wardley,Z. (1990). Lay theories of psychotherapy I: Attitudes toward, and beliefs about, psychotherapy and therapists. Journal of Clinical Psychology, 46(6): 878-890

[12] Angermeyer,M.C., And Dietrich,S. (2006). Public beliefs about and attitudes toward people with mental illness: a review of population studies. Acta Psychiatrica Scandinavica. 111(3) 163-179

[13] Economou,M., Richardson,C., Gramandani,C., Stalikas,A., and Stefanis,C.(2003). Knowledge about schizophrenia and attitudes towards people with schizophrenia in Greece. International Journal of Social Psychiatry.55(4): $361-371$

[14] Jorm,A.F., and Wright,A.M. (2008). Influences on young people's stigmatizing attitudes towards peers with mental disorders: national survey of young Australians and their parents. British Journal of psychiatry, 192(2): 144-9

[15] Ng ,S.L., Martin, J.L., and Romans, S.E.( 1995) in Kabir, M., Iliyahu,Z., Abubaker, I.S., and Aliyu, Z. (2004). Perception and beliefs about mental illness among adults in Karfi village, Northern Nigeria. BMC International Health and Human Rights.

[16] Angermeyer, M.C., and Matschinger,H.( 1996). The effect of personal experience with mental illness on the attitudes towards individuals suffering from mental disorders. Social Psychiatry and psychiatric Epidemeology. 31: 321-326

[17] Kebede,D., Alem,A., Woldesemiat,G., Jacobsson,L.,Kullgren,G.(1999). The prevalence and socio-demographic correlates of mental distress in Butajira, Ethiopia. Acta Psychiatrica Scandinivaca, 100: 5-10

[18] Kabir,M., Iliyahu,Z., Abubaker, I.S., and Aliyu,Z. (2004). Perception and beliefs about mental illness among adults in Karfi village, Northern Nigeria. BMC International Health and Human Rights. ww w. bi o me d central.co m/1472-698 X/4/3 